\title{
"I see your true colors": a diversidade dos recursos humanos no Hotel Village Premium
}

\author{
"i see your true colors": the diversity of human resources at Hotel Village \\ Premium
}

\author{
Diego Floriano da Silva ${ }^{1}$ \\ Diana Lucia Teixeira de Carvalho ${ }^{2}$
}

\begin{abstract}
Resumo
O objetivo desse caso para ensino é ilustrar um contexto no qual práticas de recursos humanos estão alinhadas a elementos da gestão da diversidade, mesmo que de maneira informal, abordando a sua difusão dentro do Hotel Village Premium, desde os gestores até seus funcionários. Para tanto, inicialmente, é feita uma breve retomada da história da rede e de seus criadores, o surgimento do hotel na cidade de João Pessoa/PB, as características dos seus setores e os acontecimentos relacionados à gestão de pessoas dentro da organização. A construção da história do caso teve embasamento nas entrevistas realizadas com funcionários do hotel e nos levantamentos feitos das condutas gerenciais dentro dele por meio de observação e conversas informais. Em termos de objetivos pedagógicos, foram elencados (a) analisar a gestão da diversidade e clima organizacional dentro da organização; (b) identificar os mecanismos, ferramentas e condutas no processo de recrutamento, seleção, treinamento e desenvolvimento; (c) analisar o modelo de gestão da diversidade e como reflete nos processos de seleção e treinamento; e (d) analisar a importância da utilização da gestão da diversidade nas organizações. A partir dos objetivos, é possível refletir e debater a respeito da diversidade, relacionando o comportamento, clima e métodos gerenciais utilizados para estimular um clima organizacional que priorize o respeito às diferenças sociais, de gêneros e às competências individuais.
\end{abstract}

Palavras-chave: Recursos humanos; gestão da diversidade; inclusão social.

\begin{abstract}
The purpose of this case is to illustrate a context in which the management of diversity occurs, albeit in an informal way, approaching its diffusion within the Village Premium Hotel, from managers to their employees. This case, therefore, deals with the Hotel Village Premium, of the Village hotel chain, and presents a brief history of the origin of the network and its creators, the emergence of the hotel in the city of João Pessoa / PB, the characteristics, its sectors, the events and fundamentals related to people management within the organization. In this sense, from the narrative of the manager of the reception sector, Sara Leite, its employee, the receptionist Leandro Almeida, and the surveys made of the managerial conducts inside the hotel, it is possible to reflect and debate about the diversity, climate and management methods used to stimulate an organizational climate that prioritizes respect for social, gender and individual competencies.
\end{abstract}

Keywords: Human resources; diversity management; organizational climate.

\section{Introdução}

Durante seu turno, o recepcionista Leandro Almeida escutou seu celular tocar. Era Sara, gerente responsável pelo setor de recepção. Simpática e sempre educada, tipo de chefe compreensiva e competente quando o assunto era comunicação e condutas, avisou que chegaria um pouco atrasada ao trabalho devido ao engarrafamento no trajeto de sua casa para o hotel. Pediu um favor a ele: um candidato à vaga de recepcionista diurno estaria chegando para passar pela entrevista de seleção.

Graduando do curso de Administração pela Universidade Federal da Paraíba (UFPB). Afiliação: UNIVERSIDADE FEDERAL DA PARAÍBA - UFPB. Brasil. Lattes: http://lattes.cnpq.br/2099837457068028 Orcid: http://orcid.org/0000-0003-4093-4943 Email: diegofloriano.silva@hotmail.com

2 Doutora e Mestre em Administração PPGA/UFPB, com ênfase em Marketing e Sociedade. Afiliação: UNIVERSIDADE FEDERAL DA PARAÍBA UFPB. Brasil. Lattes: http://lattes.cnpq.br/3069420156405414 Orcid: http://orcid.org/0000-0001-6454-8604 Email: dinda_carvalho@hotmail.com 
- Leandro, avise ao Bruno que estarei chegando uns 20 minutinhos depois do horário combinado. Diga para ele me esperar no salão. Ah, mais uma coisinha, ele não gosta de ser chamado pelo nome que está no RG.

Meio confuso com o comentário, Leandro questionou:

- Como assim "o nome no RG?" O nome dele é Diomedes, por acaso? - brincou Leandro.

- Não, Leo. O nome que ele recebeu dos pais e está registrado no RG é Brenda. Bruno é um homem trans! Ele passou por todo processo de mudança física e psicológica.

- Ahhhh, entendi! - disse Leandro. Irei recebê-lo e darei o recado. Não se preocupe com isso.

Bruno logo chegou à recepção do hotel e se dirigiu para pedir informação a respeito da entrevista. Um rapaz alto, com uma expressão apreensiva no rosto, porém muito simpático e educado.

- Olá, tudo bem? - disse Bruno. Estou procurando a Sara, que me chamou aqui para fazer uma entrevista de emprego. Onde posso encontrá-la?

- Sara pediu para lhe avisar que já está a caminho. Ela pegou um engarrafamento e por isso vai se atrasar - explicou Leandro.

Bruno então começou a conversar com Leandro enquanto esperava a gerente chegar. Rapidamente ficou à vontade com o recepcionista, de modo que começou a falar sobre sua vida e sobre o quanto estava difícil encontrar um emprego na cidade.

- Eu estou desempregado há dois anos. Trabalhava em um supermercado como recepcionista de balcão, e me destacava entre os funcionários. Porém, fui ficando desmotivado, pois não me sentia feliz comigo mesmo e isso estava afetando meu desempenho no trabalho. Não me sentia bem com meu corpo, sabe? Sentia que algo estava errado - confessou Bruno.

Leandro, apreensivo para não magoar o novo colega, perguntou com delicadeza:

- Como assim? Você é um rapaz bonito.

- O problema é que eu era mulher, mas não me sentia como uma. Percebi que minhas vontades e costumes eram diferentes, então resolvi começar o tratamento hormonal para mudança de gênero. Fui visto com maus olhos e sofri muito preconceito. Por fim, fui demitido sem motivo algum. Desde então estou desempregado - comentou Bruno, meio triste.

Em seguida, Sara chegou ao hotel cumprimentando o candidato e dando bom dia para todos. Chamou o rapaz para sua sala e começaram a entrevista. Inicialmente, foram feitas perguntas a respeito do seu último emprego e das suas experiências, e o que o trazia ao hotel. Depois, ele fez uma prova sobre conhecimentos hoteleiros e gerais. Terminados os procedimentos de seleção, Sara ficou surpresa com a personalidade e competência de Bruno para o cargo e, consequentemente, resolveu contratá-lo imediatamente.

Depois de um tempo, quando Bruno já havia ido embora e Leandro se arrumava para finalizar mais um dia de trabalho, Sara parou no corredor lateral que dava acesso à sala do departamento.

- Sarinha, eu estava pensando aqui uma coisa. Desde que eu entrei aqui, venho acompanhando as ações de todos os gerentes e como vocês se portam desde a seleção até o treinamento de seus funcionários.

- Sim, o que tem? - questionou Sara.

- Então, acredito que a equipe de gerentes aqui no hotel segue um padrão de valores humanos que entende o funcionário como uma parte da organização e prega a não discriminação, seja ela qual for. Mas, me diga uma coisa: caso vocês saiam daqui, por seja qual for o motivo, o que aconteceria com os futuros contratos?

Curiosa com o assunto, Sara tenta compreender e pede para Leandro continuar seu raciocínio.

- Prossiga - ela diz.

- O que eu gostaria de saber é: com o ingresso dos novos gerentes, pessoas como eu e Bruno teriam as mesmas oportunidades de emprego, respeito e valorização que vocês oferecem hoje para nós? 


\section{0 início da rede Village}

Era o ano de 1989. Tudo estava tranquilo na manhã de uma quarta-feira ensolarada na cidade de Garanhuns, no estado de Pernambuco. Era mês de São João, uma data que muitos da região comemoram com festas, comidas típicas e muita tradição nordestina. Época também que atrai muitos turistas e investimentos para a cidade, sendo uma estação farta para todos os comerciantes e empresários locais.

José Couto de Oliveira Filho e Marly Domingos Couto, casal morador antigo e conhecido da pequena cidade do agreste pernambucano, estavam admirados com o fluxo de visitantes, nacionais e internacionais, na sua cidade. O senhor José, um homem visionário, juntamente com sua esposa, teve uma ideia empreendedora. Ideia essa que iria contribuir com o turismo da cidade e ajudar a comportar mais turistas para a região, principalmente em datas festivas. Surgiu, então, o Hotel Village, um hotel familiar e bem localizado no centro da cidade. Com uma estrutura moderna, harmonizada e serviços altamente qualificados para seus clientes, destacou-se entre os demais hotéis da região pela simplicidade e seriedade da organização e pelo bom atendimento, consolidando-se como uma das principais redes hoteleiras regionais.

Diante de todo o sucesso e crescimento dentro da cidade de Garanhuns, o senhor José resolveu expandir para outras cidades onde o turismo estava evoluindo e precisava de uma estrutura hoteleira diferenciada para os seus clientes. Para tanto, o senhor José confiou aos seus três filhos a missão de gerenciar os dez empreendimentos que compõem a Rede Village e que geram mais de 300 empregos diretos e cerca de 500 indiretos nos estados nordestinos de Pernambuco, Ceará e Paraíba.

No ano de 2017, cada filho era o responsável por um grupo de hotéis. Os três supervisionam, para cada grupo de hotéis sob sua responsabilidade, grupos de pessoas capacitadas que ocupam o cargo de gerente dos setores existentes, e respondem ao senhor José, que foi morar em Miami há cinco anos.

Apesar de distante, o senhor José entende que sua rede hoteleira possui uma visão de gestão diferenciada dos padrões já vistos nas empresas do ramo e valoriza essa perspectiva, exigindo cumprimento desses valores pelos seus filhos e colaboradores. As práticas de gestão de pessoas aplicadas nos procedimentos de recrutamento, seleção, contratação de funcionários, até o processo de treinamento e a efetivação, são executadas de maneira que as competências, os interesses e o compromisso se sobressaiam aos preconceitos em geral, no intuito de destacar o potencial do candidato e suas habilidades para os cargos.

\section{A rede Village chega em João Pessoa: O Village Premium}

No ano de 2004, em João Pessoa, na Paraíba, foi inaugurado o Hotel Village Premium em uma localização privilegiada no bairro de Tambaú, próximo ao Busto de Tamandaré. Alguns meses antes da inauguração do hotel, Luziana Cunha foi selecionada para o cargo de gerente administrativa, mediante suas competências e aptidões, ficando sob a supervisão de Gustavo Couto, um dos filhos do senhor José. Ela, então, utilizou os mesmos critérios para a seleção dos gestores que lhe acompanhariam nessa nova missão dada pelo senhor José e por Gustavo, formando sua equipe de acordo com os cinco principais setores.

O hotel é estruturado em setores de A\&B (alimentos e bebidas), reservas, recepção, governança e segurança, para que seja desenvolvido um trabalho profissional e de qualidade. Assim, possuem gestores treinados e capacitados para desenvolverem qualquer tipo de processo necessário. No setor de reservas, Vivianne Coelho é a responsável por acolher todas as solicitações de hospedagem, processá-las e encaminhálas para a recepção. Já no setor de recepção, Sara Leite tem como função essencial gerenciar as reservas, o registro dos hóspedes, a manutenção das contas dos hóspedes, o atendimento permanente durante a hospedagem e o procedimento de saída e acerto de contas.

No setor de governança, Antônia é responsável por distribuir as tarefas de limpeza dos apartamentos, dos corredores e das áreas públicas, e por assegurar o bem-estar dos hóspedes. Além disso, fornece uniformes para todos os funcionários, cuida da seção de achados e perdidos, da roupa de mesa para o setor A\&B, da lavanderia, da manutenção, da decoração, e administra os pedidos de compras de roupas, como lençóis e toalhas, de equipamentos e materiais de limpeza e de móveis.

O setor de segurança do hotel é composto por uma equipe terceirizada para monitoramento $24 \mathrm{~h}$, que garante a segurança dos funcionários e hóspedes. Luziana Cunha é responsável pelo setor de A\&B, por 
meio do controle e da organização dos bares e restaurante, da cozinha e seus serviços agregados. Luziana é, ainda, a gerente administrativa do hotel, supervisionando toda a equipe de gestores e reportando-se diretamente a Gustavo, diretor do hotel. Os gestores do hotel possuem autonomia para gerenciar suas equipes e solucionar problemas referentes aos seus setores, tendo que reportar à Luziana apenas casos graves ou de urgência, para que sejam solucionados ou repassados para alta gerência do hotel.

O Hotel Village Premium, além dos gestores em seus respectivos setores, conta com uma equipe de funcionários composta por: 7 camareiras; 4 recepcionistas e 1 estagiário; 1 administrador financeiro; 4 funcionários nos serviços gerais; 7 no setor de A\&B; 1 menor aprendiz; 1 almoxarife; 4 funcionários na manutenção; 6 manobristas e 3 no setor de reservas, totalizando 37 funcionários treinados e capacitados, divididos em dois turnos, diurno e noturno, em um ambiente de trabalho tranquilo e com um clima organizacional fluido, em prol do objetivo de oferecer serviços qualificados aos seus clientes. Sua diretriz estratégica é sempre trazer conforto e tranquilidade aos seus clientes e investidores, agregando valores, credibilidade e excelências em todos os seus serviços prestados. Com isso, destaca-se no mercado hoteleiro de João Pessoa pelo seu diferencial em atendimento, estrutura, gestão e serviços, alcançando a posição de $4^{\circ}$ melhor hotel do estado da Paraíba.

\section{A recepção recepciona a diversidade}

No setor de recepção do Hotel Village, Sara Leite atua há quatro anos como gerente. No começo de sua carreira, recebeu a proposta para trabalhar como recepcionista, mas, ao se destacar rapidamente por suas competências, foi promovida ao cargo da gerente. Dentre as funções que acredita ser a de maior responsabilidade, está a gestão do pessoal encarregado da recepção. De fato, ela lida com diversos tipos de personalidades e deve disseminar os valores que a empresa apresenta nas suas diretrizes.

Com foco no respeito à diversidade e na busca por competências necessárias para alcançar os objetivos estratégicos do hotel, Sara explica que, quando alguém chega com currículo em mãos, já consegue observar se o candidato possui o perfil que precisam. Com isso, seleciona os funcionários da sua equipe sem fazer distinção de raça, gênero, deficiência, determinação sexual ou qualquer outro tipo de característica. "Não vejo se é homossexual ou heterossexual, eu vejo o profissional em si", diz a gerente.

Gestores de outros setores seguem os mesmos critérios de recrutamento e seleção, oportunizando uma diversidade ao seu staff, pois, como Sara explica, a política do hotel sempre foi de respeito e reconhecimento profissional e pessoal. Com foco nesse pressuposto, nunca houve problema em relação a preconceitos de qualquer tipo. "O clima que criamos dentro do nosso trabalho é muito positivo e acolhedor. Os valores e condutas das pessoas refletem no seu trabalho, as escolhas pessoais, não", Sara ressalta.

No setor da recepção, sob a chefia de Sara, Leandro Almeida é um funcionário exemplar. Conhecido de Sara, ele foi recrutado por ela para ser estagiário e, após os processos de seleção, não só foi contratado, como foi efetivado dois meses após iniciar seu trabalho no hotel. Sara lembra que, na época, precisava de alguém de confiança e que fosse competente para a função, e que Leandro foi a primeira pessoa que veio em mente, pois ela só enxergava a capacidade que ele tinha para compor a sua equipe.

Mas, para Leandro, que é homossexual, o local de trabalho nem sempre foi acolhedor. Começou a trabalhar muito novo, conciliando o seu trabalho com os estudos. O primeiro trabalho foi em uma secretaria do estado da Paraíba, e lá se via muito retraído e pouco à vontade para se expressar. Apesar de tranquilamente aceitar sua determinação sexual, Leandro tinha receio de dialogar com seus colegas de trabalho, pois sentia diferença no tratamento que recebia deles. O preconceito era velado.

Ao ser contratado por sua amiga, Sara, ele começou a experimentar outro tipo de clima organizacional. Após os primeiros meses de adaptação, observou o quão diferente era do seu trabalho anterior, pois os seus colegas atuais eram comunicativos e receptivos, e ele não sofria indiferenças dentro da empresa. Desde sua contratação como estagiário, passando por sua efetivação e treinamento, ele se sentia parte do hotel e via o quanto era admirado por suas competências e humanismo.

Leandro, depois de conhecer Bruno e ver sua dedicação para manter quem ele é ao mesmo tempo em que procurava oportunidades de emprego, começou a refletir sobre tudo que já havia passado na sua vida profissional e pessoal. Essa reflexão o fez questionar Sara: 
- Sara, me tira uma dúvida. - diz Leandro.

- Claro que sim, galego. - confirma Sara.

- Vendo o novato Bruno, e depois da pequena conversa que tive com ele, fiquei curioso sobre o futuro. Digo, quando vocês gestores saírem e outros entrarem, será que estes terão a mesma visão para seguir o modelo que vocês usam aqui no hotel? - questiona Leandro

- Por quê? Você acha que o modelo de seleção e treinamento que utilizamos já não está fixado no Hotel Village? - rebate Sara com outra pergunta.

\section{As práticas de gestão de pessoas do hotel Village Premium}

O Hotel Village Premium possui a ideologia de atuar com o espírito de equipe, no intuito de desenvolver e aplicar programas de alcance social, sejam externos, por meios de ações filantrópicas na comunidade do Jacaré e no Novo Horizonte - Missão Atalaia, sejam internos, por meio de valorização do pessoal e de um trabalho em equipe direcionado para o cooperativismo e política de não discriminação e valorização do ser humano. A conduta de responsabilidade social está inerente de forma implícita nas políticas organizacionais do estabelecimento. O comprometimento se evidencia nos processos de recrutamento, seleção, contratação e treinamento, assim como na ética e no aprendizado das ações diárias, que se alinham ao código de ética que é compartilhado por todos os gestores e funcionários na direção da valorização do ser humano, independentemente de suas características de raça, etnia, deficiência, determinação sexual ou gênero.

O gestor de cada setor da organização possui autonomia para gerenciar os processos de recrutamento, seleção, contratação, treinamento, aprendizado, capacitação e orientação dos seus funcionários. Entretanto, de modo geral, eles utilizam tacitamente certos indicadores nos processos: pautar suas ações de contratação na qualificação e nas competências profissionais do candidato e em seu comportamento ético; praticar a seleção respeitando a diversidade dos candidatos; desenvolver, avaliar, promover e remunerar por meio de aplicação justa de políticas vigentes; e estimular o clima de confiança, respeito, honestidade e credibilidade entre líderes, liderados e colegas. Desse modo, Sara entende que há uma clareza na cultura organizacional de valorização e incentivo de humanização.

Existem duas maneiras de contratação dentro do hotel. A primeira é pela categoria de estágio, em parceria com o Centro de Integração Empresa Escola - CIEE, com intenção de oportunizar alunos universitários a ingressarem no mercado de trabalho. A segunda é participando do processo de seleção para efetivação enquanto funcionário. A principal diferenciação na seleção ocorre no que diz respeito ao ingresso dos funcionários e estagiários, pois aqueles que pretendem ingressar como funcionários são submetidos à avaliação de uma psicóloga vinculada ao hotel, responsável por analisar se suas competências e valores estão alinhados às políticas e práticas da organização.

Desse modo, os funcionários que passam pelo processo de seleção, com o aval da psicóloga, são efetivados e seguem para uma rotina de 360 horas de treinamento, o qual foca, prioritariamente, no aprendizado compartilhado entre os funcionários mais antigos e na orientação do gestor responsável pelo setor. Para que se mantenham competitivos e qualificados para o mercado, os gestores promovem capacitações para os seus funcionários uma vez por ano ou quando houver necessidade emergencial.

Nesse sentido, as diretrizes do hotel aplicadas em todos os setores e repassadas por meio de condutas, políticas e aprendizados se direcionam para uma cultura organizacional focada em conhecimentos, habilidades, competências e valores do ser humano. Os funcionários que compõem a equipe do hotel, com suas características diversas, acreditam que são respeitados e valorizados no seu ambiente de trabalho, e isso faz toda a diferença na relação com os parceiros e clientes.

A conduta utilizada pela gestão gerou, de forma indireta e sem definição concreta estabelecida anteriormente, um programa de diversidade que hoje faz parte da cultura organizacional do hotel. Por isso, ao ser questionada por Leandro sobre a possibilidade de o respeito à diversidade ser banido das equipes do Hotel Village Premium, Sara reflete se não está na hora de registrar, em algum tipo de manual, as práticas e políticas que fundamentam tacitamente as ações de recursos humanos do hotel. Mas será mesmo preciso? 


\section{NOTAS DE ENSINO}

\section{Objetivos educacionais}

O caso foi criado para debater, dentro das temáticas de gestão de pessoas e com ênfase nas minorias no ambiente de trabalho, as políticas de recursos humanos aplicadas, as oportunidades de crescimento profissional, e quais as implicações da gestão da diversidade para o clima organizacional de uma empresa. A aplicação do caso é sugerida em cursos de graduação e pós-graduação, tanto lato sensu quanto stricto sensu, especialmente em Administração e Hotelaria, com foco nas disciplinas de Gestão de pessoas e Comportamento organizacional.

Especificamente, o caso objetiva: (a) analisar a gestão da diversidade e clima organizacional dentro da organização; (b) identificar os mecanismos, ferramentas e condutas no processo de recrutamento, seleção, treinamento e desenvolvimento; (c) analisar o modelo de gestão da diversidade e como reflete nos processos de seleção e treinamento; e (d) analisar a importância da utilização da gestão da diversidade nas organizações.

A partir desses objetivos, o professor pode levar os alunos a refletir sobre a gestão de pessoas, vista como uma importante aliada na criação de mecanismos que possam efetivar o amplo processo da inclusão da diversidade, assim como sobre os modelos de gestão da diversidade e do conhecimento e métodos utilizados para produzir resultados positivos para a empresa. Esse entendimento é relevante, posto que os gestores precisam desenvolver competências imprescindíveis para gerenciar a mudança cultural e de atitudes em prol de uma melhor eficiência organizacional.

A participação dos alunos na análise do caso pode desenvolver competências relativas ao amadurecimento empresarial, com foco no conhecimento de questões como: modelos organizacionais utilizados para unificar o clima entre funcionários, clientes e superiores; diretrizes utilizadas e política formal da organização; diversidade nas organizações; processo de contratação, suas exigências e utilização das ferramentas de gestão de pessoas da empresa; métodos de gestão de pessoas para avaliar, posicionar, aperfeiçoar e capacitar a equipe; e conscientização das relações humanas e sua importância para a dissipação dos preconceitos já existentes. Além disso, os alunos poderão criar uma nova visão de como lidar com grupos organizacionais, não só dentro como fora das empresas, de maneira inclusiva.

\section{Fonte de dados}

Para a realização desta pesquisa, foram coletados dados por meio de uma entrevista semiestruturada e presencial com a gerente do setor de recepção do hotel e por meio de conversas informais por áudio gravadas em uma ferramenta de comunicação, utilizando aparelhos celulares com funcionários. Todas as quatro entrevistas ocorreram no mês de setembro de 2017 e foram gravadas com prévia autorização. A primeira entrevista foi feita com a gerente de recepção, Sara Leite, e as demais com a gerente geral, Luziana Cunha. As entrevistam versaram a respeito das políticas organizacionais, do clima e da gestão da diversidade utilizadas na contratação e treinamento, além de buscar entender a opinião geral das gestoras sobre o tema abordado. As entrevistas tiveram uma duração média de $1 \mathrm{~h} 20 \mathrm{~min}$. Conversas informais com outros funcionários, de diversos setores, como A\&B, recepção e governança ocorreram mediante a observação feita no hotel durante 5 dias, em setembro de 2017. Além disso, foram obtidos áudios enviados pelo aplicativo de comunicação WhatsApp, nos quais os funcionários comentavam sobre suas experiências antes e depois do ingresso na empresa e seus pontos de vista em relação ao tema abordado. A troca de informações via WhatsApp foi feit,a principalmente, com Leandro Almeida, uma vez que ele se manteve disponível para fornecer informações complementares durante todo o processo de elaboração deste caso. Todas as entrevistas foram autorizadas a serem analisadas e transcritas para objetivos acadêmicos. Informações gerais sobre o hotel e depoimentos breves de clientes, assim como o site da própria empresa, também subsidiaram a elaboração do caso. 


\section{Tópicos pedagógicos}

Para direcionar a aplicação deste caso, recomenda-se que o professor, inicialmente, explique aos alunos os procedimentos para utilização do método de caso em sala de aula, estimulando o comprometimento com a estratégia de ensino. Em seguida, é interessante que seja recomendada a leitura prévia do caso como atividade, bem como que os alunos elaborem respostas individuais às questões propostas.

$\mathrm{Na}$ aula seguinte à explicação da metodologia, sugere-se que o professor separe os alunos em pequenos grupos, de 3 a 4 pessoas, a depender do tamanho da turma, estimulando entre eles o debate sobre as respostas individuais das questões descritas no caso. Recomendase que o tempo disponível para a atividade seja de 30 a 45 minutos.

Para o debate em plenária, após a discussão nos pequenos grupos, indica-se dispor a turma em um círculo e solicitar que cada grupo apresente oralmente a sua análise. De acordo com o professor, pode ser solicitado que os alunos se posicionem individualmente. Tal atividade, dependendo do tempo disponível para a aula, pode durar cerca de 80 minutos, para que cada questão possa ser debatida por um tempo mínimo de 20 minutos. Nesse momento, espera-se que o professor fomente a discussão entre os alunos, de modo a estimular a participação de todos.

Finalmente, sugere-se que o professor realize um fechamento do caso para ensino estudado, propondo direcionamentos para a análise a partir das opiniões manifestadas pelos alunos e discutindo as alternativas propostas por eles. O professor pode, inclusive, utilizar o quadro para elencar as alternativas propostas pelos alunos, de modo a ficar visível para toda a turma.

Em termos avaliativos, entende-se que os alunos podem ter sua avaliação decomposta em dois momentos, assim pontuando a participação nas discussões nos pequenos grupos e em plenária, bem como a elaboração prévia das respostas às questões, que devem ser entregues individualmente. Mesmo sendo solicitado aos grupos que produzam uma única resposta durante as discussões, acredita-se que as respostas individuais representam o real desempenho preparatório do aluno para a atividade.

\section{Questões para discussão}

Com o intuito de orientar as discussões sobre o caso, sugerem-se quatro questões que podem ser utilizadas mediante critérios estabelecidos pelo professor, de acordo com a adequação ao conteúdo apresentado em sala de aula:

1. Na sua opinião, existe consolidação dos valores organizacionais no Hotel Village Premium? Imagine que você é um funcionário do Hotel Village Premium. Você acredita que há consolidação e entendimento coletivo sobre a diversidade como valor organizacional? Como esse valor norteia as ações e o quanto está enraizado no comportamento organizacional?

2. Para você, há relação entre a gestão da diversidade, a inclusão social e a melhoria do desempenho organizacional? Como isso pode ocorrer nas organizações? E no Hotel Village Premium?

3. As políticas e práticas de gestão de pessoas são importantes aliadas para a garantia da gestão da diversidade, da participação plena do funcionário, da valorização da sua potencialidade humana e da sua capacidade produtiva. Com base nessa afirmação, discorra sobre como as políticas e práticas de gestão de pessoas podem auxiliar a gestão da diversidade.

4. Considere um contexto organizacional com grande inserção de funcionários com diversidade de características físicas, sociais e intelectuais. Como você entende a importância de os gestores dessa organização possuírem uma formação profissional em Administração que tenha abordado esse tipo de gestão de pessoas?

\section{Análise do caso e conexão com a literatura}

Nesta seção, as questões sugeridas são exploradas mediante relação do contexto do caso com a revisão da literatura que as embasam. A finalidade é apresentar ao professor o conteúdo pensado para cada questão, de modo a direcionar a sua utilização. 
1. Na sua opinião, existe consolidação dos valores organizacionais no Hotel Village Premium? Imagine que você é um funcionário do Hotel Village Premium. Você acredita que há consolidação e entendimento coletivo sobre a diversidade como valor organizacional? Como esse valor norteia as ações e o quanto está enraizado no comportamento organizacional?

Nesta questão, o aluno irá discorrer a respeito dos valores organizacionais, trazendo sua reflexão e importância para o ambiente competitivo no qual o Hotel Village Premium atua. Os valores, dentro da cultura organizacional, norteiam o comportamento do indivíduo. Ao analisar a história e o comportamento, desde a seleção até a efetivação dos funcionários no Hotel Village Premium, o aluno pode observar que, em todos os níveis hierárquicos do hotel, há valorização dos funcionários como pessoas, de modo que são percebidos mediante suas competências individuais que satisfazem aos objetivos da organização, e não características físicas, sociais e culturais.

Nesse sentido, Veiga (2010) argumenta que os valores organizacionais possuem forte influência na construção social das organizações, estimulando a integralidade de seus interesses e práticas na cultura organizacional em diversos níveis (artefatos, valores e pressupostos básicos) por meio do compartilhamento, do domínio e do desenvolvimento do processo de aprendizagem da cultura. Com efeito, os valores organizacionais são intrínsecos à cultura organizacional que, por sua vez, está inclusa na gestão de pessoas, sendo destacados padrões de comportamento e ações como resultado da socialização dos funcionários na realização de suas atividades e compartilhamento de experiências e expectativas (GUARDANI et al., 2013). O aluno pode, ainda, afirmar que, ao mesmo tempo em que a estrutura da organização evolui, a sua cultura organizacional, que é o conjunto de valores compartilhados e normas que controlam as interações de membros da organização entre si (expandidos para os fornecedores, clientes e outras pessoas de fora dela) também se aperfeiçoa. Como pode ser modelada pelas pessoas, pela ética, pelos direitos trabalhistas concedidos aos empregados, pela estrutura que a organização possui, a cultura organizacional adapta e controla o comportamento dentro da organização, o que influencia a maneira como as pessoas respondem a uma situação e como interpretam o ambiente ao redor da organização (GARETH, 2010).

Assim, é possível que o aluno afirme que os valores organizacionais relativos à diversidade estão consolidados na dinâmica organizacional coletiva do hotel, por meio de condutas e práticas que priorizam a atuação do funcionário como um sujeito único, capaz de gerar valor para a organização por meio das suas características e competências. Todavia o aluno pode argumentar que as práticas associadas à diversidade podem se tornar mais concretas com a criação de um manual organizacional ou por meio do desenvolvimento, de forma mais elaborada, da gestão direcionada à diversidade.

\section{Para você, há relação entre a gestão da diversidade, a inclusão social e a melhoria do desempenho organizacional? Como isso pode ocorrer nas organizações? E no Hotel Village Premium?}

Esta questão tem o objetivo de fazer com que o aluno discuta o papel da gestão da diversidade na inclusão social, com foco na implementação dentro das organizações, de modo que ele possa também avaliar a importância desses valores para o desempenho organizacional. Para tanto, pode argumentar que a inclusão é consequência desse tipo de gestão, sendo capaz de gerar benefícios dentro e fora do ambiente de trabalho para todos os envolvidos. Isto porque, como afirma Cox (1994), a gestão da diversidade traz resultados positivos para a empresa, posto que permite a diversificação da mão de obra, promovendo a criatividade e a inovação, além de desenvolver a flexibilidade do sistema administrativo, o que pode gerar vantagens competitivas para a organização. O aluno pode dizer, ainda, que é necessário que as empresas incorporem a gestão estratégica do capital humano nas práticas administrativas, de modo a ampliar o potencial inovador de seus colaboradores, além de melhor tratar a gestão da diversidade (MEDEIROS et al, 2014).

Dessa forma, quando o assunto em pauta é sobre diversidade, comumente surgem debates que norteiam a importância da inclusão, a qual está diretamente interligada à valorização das pessoas, independentemente de seus estados sociais, intelectuais, sexuais, de gênero, de crença e etnia, abordando inclusive uma questão ética (BORIN; FIENO; SAMPAIO, 2015). Nesse sentido, segundo Seffner (2003) e Silva (2005), a 
diversidade dentro das organizações surge como uma questão de responsabilidade social, pois possibilita a integralização de membros de grupos categorizados como minorias dentro do ambiente organizacional. As minorias não são, nesse contexto, referências para pequenos grupos sociais, mas, sim, relacionadas pelas contraposições ao poder, desvalorização de pessoas gerada pelo preconceito racial, de gênero, sexualidade, pobreza, entre outros fatores.

Assim sendo, as organizações estariam investindo não apenas na diversificação de culturas, na retenção de melhores talentos no mercado e nas competências para alcançar melhores resultados, mas, também, estariam investindo na descriminação dentro e fora de seu ambiente, na conscientização social e na inclusão das minorias no mercado de trabalho. No contexto do Hotel Village Premium, é possível identificar a inclusão por meio da contratação de Bruno e do próprio Leandro, sendo uma prática não apenas corriqueira, mas já consolidada informalmente na gestão de pessoas da organização.

\section{As políticas e práticas de gestão de pessoas são importantes aliadas para a garantia da gestão da diversidade, da participação plena do funcionário, da valorização da sua potencialidade humana e da sua capacidade produtiva. Com base nessa afirmação, discorra sobre como as políticas e práticas de gestão de pessoas podem auxiliar a gestão da diversidade.}

Nesta questão, o aluno deve analisar a importância das políticas e práticas de gestão de pessoas para a realização de uma eficiente gestão da diversidade, descrevendo suas benfeitorias no que diz respeito à participação plena do funcionário, à valorização da sua potencialidade humana e da sua capacidade produtiva. Para se garantir a gestão da diversidade, é necessário que as organizações e gestores adaptem e reestruturem as políticas e práticas de gestão de pessoas. Tais políticas devem envolver instrumentos que permitam a adequação do profissional ao cargo a ser desempenhado e Ihes possibilitar qualificação, construção de carreira e suportes necessários para o seu crescimento pessoal e profissional dentro do ambiente de trabalho. Para tanto, as empresas precisam estar atentas às características comuns dos funcionários, mas devem administrá-los de acordo com suas características individuais (BOHLANDER; SNELL; SHERMAN, 2005).

Nessa perspectiva, Wooten (2008) salienta que, para se quebrar as barreiras da inclusão, as organizações precisam incorporar adaptações nas suas políticas e práticas de gestão de pessoas, a fim de acomodar todos os funcionários, equilibrando as necessidades profissionais e pessoais. Para Demo (2010, p. 64), as políticas e práticas de gestão de pessoas podem "contribuir para um maior bem-estar das pessoas, permitindo-Ihes maior realização pessoal e profissional". Entende-se, todavia, que as práticas de gestão de pessoas são ações que traduzem e operacionalizam as políticas, portanto, tais ações devem ser baseadas na acomodação de todos os tipos de diferenças, para que, assim, possam ser cultivadas e utilizadas em benefício da empresa (DEMO et al., 2014; BOHLANDER; SNELL; SHERMAN, 2005).

\section{Considere um contexto organizacional com grande inserção de funcionários com diversidade de características físicas, sociais e intelectuais. Como você entende a importância de os gestores dessa organização possuírem uma formação profissional em Administração que tenha abordado esse tipo de gestão de pessoas?}

Nesta questão, o aluno terá que refletir sobre a importância do domínio das práticas de gestão da diversidade nas organizações, mostrando seus benefícios ao absorver tais práticas ao aprimoramento profissional e ético. Na justificativa, o aluno deverá demonstrar a compreensão de que o profissional de administração que detém conhecimento sobre a gestão da diversidade será capaz de extrair o melhor de cada funcionário e, como consequência, poderá obter vantagem competitiva relacionada aos seus recursos humanos. Ao entender que cada ser humano é único, a diversidade nas empresas representa o reconhecimento dessas diferenças no modo de ser, pensar e agir de cada profissional e a valorização dessa união no ambiente de trabalho. Além disso, pode argumentar que se todos fossem iguais não haveria ideias diferentes, de modo que os resultados das organizações seriam sempre os mesmos, e não existiriam 
avanços e nem melhorias. Nesse contexto, a diversidade é o caminho para que as empresas se tornem inovadoras, com a capacidade de produzir bens úteis e possibilitar que seus funcionários sejam incluídos e estejam realizados e motivados. O papel do gestor é de compreensão da diversidade como uma das premissas da sociedade, e que sem ela é impossível ter sucesso social.

Deve ser, ainda, levado em consideração que, apesar de uma empresa buscar resultados econômicos, não deve implantar políticas de diversidade apenas como estratégias dedicadas exclusivamente a metas financeiras, e sim como um compromisso moral que a empresa assume com a sociedade, entendendo que, antes de ser funcionário, o colaborador é um cidadão e deve ter sempre seus direitos sociais garantidos, como o de ser respeitado nas suas diversas características pessoais (SANTOS; SANTANA; ARRUDA, 2018). Portanto, a inteligência na aplicabilidade da gestão da diversidade, seja direta, seja indireta, está em unir as competências e habilidades de sua equipe e usar essa prática de forma complementar, unindo suas expertises, com o objetivo de aumentar a produtividade e potencializar os sucessos, tanto individual como grupal, dentro da organização.

No entanto, de acordo com Alves e Galeão-Silva (2004), no Brasil, principalmente por questões socioculturais, há uma dificuldade em alcançar o equilíbrio das práticas de gestão da diversidade, o que demonstra a importância desse tipo de tema na formação do administrador. A importância do tema da gestão da diversidade no currículo de graduação em Administração é discutida por Pinheiro e Gois (2012), os quais argumentam ser fundamental que os egressos possuam conhecimento sobre as práticas de diversidade, de modo que saibam lidar com os desafios que o contexto organizacional pode apresentar pela sua dinamicidade, complexidade, humanidade e pluralidade. Assim, os alunos que têm acesso a esse tipo de discussão na graduação podem ser considerados como conscientes e capacitados sobre o processo contínuo pelo qual se expressa a gestão da diversidade.

\section{Referências}

ALVES, M. A.; GALEÃO-SILVA, L. G.. A crítica da gestão da diversidade nas organizações. RAE-revista de administração de empresas, v. 44, n. 3, p. 20-29, 2004.

BORIN, F.; FIENO, P.; SAMPAIO, B. Diversidade: inclusão ou estratégia. Harvard Business Review, v. 93, n. 10, p. 58-62, 2015.

COX, T. Cultural diversity in organizations:theory, research \& practice. San Francisco: Berrett Koehler, 1993

COX, T.. Cultural diversity in organizations: Theory, research and practice. Berrett-Koehler Publishers, 1994.

JONES, G. R. Teoria das organizações. São Paulo: Pearson Education do Brasil, 2010.

GUARDANI, F.; TEIXEIRA, M. L. M.; DE SOUZA BIDO, D.; MAZZON, J. A. A relação entre valores, práticas organizacionais e confiança de clientes no setor de serviços. Production, v. 23, n. 4, p. 806817, 2013.

MEDEIROS, G. T. C.; FERREIRA, W. L. S.; SOUZA, A. R.; REIS, P. N. C; FARIA, L. C. S. A diversidade nas organizações contemporâneas: um enfoque na transversalidade de gênero.In: Simpósio de

Excelência em Gestão e Tecnologia. 11., 2014, Resende. Anais eletrônicos. Resende: AEBD, 2014.

REDE DE HOTÉIS VILLAGE. Disponível em <http://www.hoteisvillage.com.br/ village/> Acesso em: 22 de mai 2017.

SANTOS, J. V. M; SANTANA, A. C.; ARRUDA, G. D. A. Diversidade nas organizações: inclusão social ou estratégia competitiva?Psicologia.pt, 2018.

SANTOS, G.; DA SILVA, M. P.. Racismo no Brasil: percepções da discriminação e do preconceito racial no século XXI. Editora Fundação Perseu Abramo, 2005.

SEFFNER, F.. Derivas da masculinidade: representação, identidade e diferença no âmbito da masculinidade bissexual. Paco Editorial, 2016. 
THOMAS, R. R. From affirmative action to affirmative diversity. Harvard Business Review, Mar./Apr, p. 107-118, 1990.

VEIGA, H. M. S. Comportamento pró-ativo: relações com valores organizacionais, estímulos e barreiras à criatividade nas organizações e normas sociais. 2010. 249 f. Tese (Doutorado em Psicologia Social, do Trabalho e das Organizações). Universidade de Brasília, Brasília, 2010.

ALVES, M. A.; GALEÃO-SILVA, L. G.. A crítica da gestão da diversidade nas organizações. RAE-revista de administração de empresas, v. 44, n. 3, p. 20-29, 2004.

BORIN, F.; FIENO, P.; SAMPAIO, B. Diversidade: inclusão ou estratégia. Harvard Business Review, v. 93, n. 10, p. 58-62, 2015.

BOHLANDER, G. W.; SNELL, S.; SHERMAN, A. Administração de Recursos Humanos. São Paulo: Pioneira Thomson Learning, 2005.

COX, T.. Cultural diversity in organizations: Theory, research and practice. Berrett-Koehler Publishers, 1994.

DEMO, G. Políticas de gestão de pessoas, valores pessoais e justiça organizacional. Revista de Administração Mackenzie, São Paulo, v. 11, n. 5, p. 55-81, set./out., 2010.

DEMO, G.; NEIVA E. R.; NUNES, I.; ROZZETT, K. Políticas e Práticas de Recursos Humanos. In: SIQUEIRA, M. M. M. Novas medidas do comportamento organizacional: ferramentas de diagnóstico e de gestão. Porto Alegre: Artmed, 2014. p. 240-255.

GARETH, J. E. Teorias das organizações. São Paulo: Pearson Education do Brasil, 2010.

GUARDANI, F.; TEIXEIRA, M. L. M.; DE SOUZA BIDO, D.; MAZZON, J. A. A relação entre valores, práticas organizacionais e confiança de clientes no setor de serviços. Production, v. 23, n. 4, p. 806817, 2013.

MEDEIROS, G. T. C.; FERREIRA, W. L. S.; SOUZA, A. R.; REIS, P. N. C; FARIA, L. C. S. A diversidade nas organizações contemporâneas: um enfoque na transversalidade de gênero.In: Simpósio de Excelência em Gestão e Tecnologia. 11., 2014, Resende. Anais eletrônicos. Resende: AEBD, 2014.

SANTOS, J. V. M; SANTANA, A. C.; ARRUDA, G. D. A. Diversidade nas organizações: inclusão social ou estratégia competitiva?Psicologia.pt, 2018.

SANTOS, G.; DA SILVA, M. P.. Racismo no Brasil: percepções da discriminação e do preconceito racial no século XXI. Editora Fundação Perseu Abramo, 2005.

SEFFNER, F.. Derivas da masculinidade: representação, identidade e diferença no âmbito da masculinidade bissexual. Paco Editorial, 2016.

VEIGA, H. M. S. Comportamento pró-ativo: relações com valores organizacionais, estímulos e barreiras à criatividade nas organizações e normas sociais. 2010. 249 f. Tese (Doutorado em Psicologia Social, do Trabalho e das Organizações). Universidade de Brasília, Brasília, 2010.

WOOTEN, L. P. Breaking barriers in organizations for the purpose of inclusiveness. Human Resource Management, v. 47, n. 2, p. 191-197, 2008.

Submetido em: 19/12/2018

Aprovado em: 30/07/2019 